\title{
The Famous Coin Change Problem and its Possible New Applications
}

Quang Vu
University of South Florida, quang1@usf.edu

Advisors:

Arcadii Grinshpan, Mathematics and Statistics

Schinnel Small, Computer Science and Engineering

Problem Suggested By: Quang Vu

Follow this and additional works at: https://digitalcommons.usf.edu/ujmm

Part of the Mathematics Commons

UJMM is an open access journal, free to authors and readers, and relies on your support:

Donate Now

\section{Recommended Citation}

Vu, Quang (2020) "The Famous Coin Change Problem and its Possible New Applications," Undergraduate Journal of Mathematical Modeling: One + Two: Vol. 11: Iss. 1, Article 5.

DOI: https://doi.org/10.5038/2326-3652.11.1.4924

Available at: https://digitalcommons.usf.edu/ujmm/vol11/iss $1 / 5$ 


\title{
The Famous Coin Change Problem and its Possible New Applications
}

\begin{abstract}
The classical problem "Coin change" in Computer Science has become a key problem to a number of subsequent problems in different areas: finance, algorithm study, sports, etc. Mathematicians have been paying attention to only two possible outcomes of the problem: the most time/resource efficient solution and the total number of solutions. However, solutions among the "normal solutions" can be beneficial in certain situations, if carefully considered with math and economic phenomena in the past. Our work describes some of such possible beneficial solutions that are worth paying attention to and its application in finance and fiscal policy. Now it is of particular importance because of COVID-19 pandemic.
\end{abstract}

\section{Keywords}

finance, fiscal policy, notes, coin change, dynamic programming

\section{Creative Commons License}

(c) (i) $\Theta$

This work is licensed under a Creative Commons Attribution-Noncommercial-Share Alike 4.0 License. 


\section{PROBLEM STATEMENT}

The famous problem "Coin change" in Algorithm Study has led to many subsequent problems and applications in different areas, including computational theory, finance, sport, etc. The number of possible solutions for a related problem is usually large, but problem solvers only care about the most time/resource effective solution and/or the number of all possible solutions. Is so-called most effective solution always the best one, or is there a better solution that lies among the other ones in some real situations? As of today it is important while the US has been combating with COVID-19 pandemic.

\section{MOTIVATION}

Theoretically, the "coin change" or "change-making" problem always has more than one solution. However, only the total number of solutions and the "best solution" (usually the most time/resource efficient solution) is considered applicable to reality. However, there exist many phenomena and conditions showing that sometimes not-the-best solution might be the best solution to the problem. Our work shows some examples when this statement may become applicable.

\section{MATHEMATICAL DESCRIPTION AND SOLUTION APPROACH}

The "Coin change" problem states that for a positive value of money $n(n>0, n \in N)$ and a sequence of $\mathrm{k}$ types of notes that have values $a_{1}, a_{2}, \ldots, a_{k}$ (with $n>a_{1}>a_{2}>\ldots>a_{k}>0 ; a_{1}, a_{2}, \ldots, a_{k} \in N$ ), a possible way to divide the amount of $n$ into smaller notes is when there exists a set $\mathrm{X}$ consisting of $\mathrm{k}$ values $\left(x_{1}, x_{2}, \ldots, x_{k}\right)$ that respectively resembles the number of each type of cash notes necessary to sum up into $n$ :

$$
n=\sum_{i=0}^{k} a_{i} x_{i}
$$

There are many ways that can be used to make the big problem modelized. When $a_{1}, a_{2}, \ldots, a_{k}$ are coprime pairs, the problem has very few possible solutions. However, in most monetary systems, 
$\operatorname{GCD}\left(a_{i}, a_{i+1}, a_{i+2}\right)=10^{\alpha}$,

with $(\mathrm{k}-i-2) \equiv 1(\bmod 3)$ and $\frac{a_{i+2}}{10^{\alpha}} \equiv 1(\bmod 10), \frac{a_{i+1}}{10^{\alpha}} \equiv 2(\bmod 10), \frac{a_{i}}{10^{\alpha}} \equiv 5(\bmod 10)$.

Because this characteristic repeats after every three values of note, the problem of dividing $n$ into different note values can be modelized as finding the number of ways of dividing 10 into 1,2 and 5, which means

$$
n=\sum_{i=1}^{k} t_{i} 10^{i} \quad\left(t_{i} \text { is the }(\mathrm{k}-i+1)^{\text {th }} \text { number in }\right)
$$

When trying to create a model for the problem, we recognize that the bigger model includes smaller models that have the exact expressions as of themselves. Therefore, to find the fewest number of cash notes being used, we only need to consider one model:

$$
r_{i}=a_{i+1} x_{i+1}+r_{i+1}
$$

and

$$
a_{i+1} x_{i+1} \equiv r_{i+1}\left(\bmod r_{i}\right)
$$

As $i$ runs from 1 to $\mathrm{k}$, we need to solve this model $\mathrm{k}$ times, respectively resembling $\mathrm{k}$ different types of available notes. In Algorithm Study, this is called dynamic programming.

Consider an amount $x_{i}^{\prime}$ such that $x_{i}^{\prime}<x_{i}$, where $x_{i}$ is applied to $a_{i}$. It means that $x_{i+1}^{\prime}>x_{i+1}$, where $x_{i+1}$ is applied to $a_{i+1}$. Any possible solution that contains such conditions is considered a "bad solution" to the problem.

\section{DISCUSSION}

It has long been accepted that the "most effective solution" with all largest possible $x_{i}$ for each $a_{i}$ is always the best solution to this kind of problem. However, if we look at how real money notes are distributed among citizens, business premises, and banks, we can see that the "most effective solution" is no longer applied. Based on the statistics recorded by the Board of Governors of the Federal Reserve System the number of $\$ 1$ bill and $\$ 100$ bill is approximately equal at this moment and co-dominate the circulation of currency in the US at 
present. It shows that the traditional solution for the "coin change" problem cannot be applied in a bigger problem - the money circulation.

\begin{tabular}{|c|c|c|c|c|c|c|c|c|c|}
\hline & $\$ 1$ & $\$ 2$ & $\$ 5$ & $\$ 10$ & $\$ 20$ & $\$ 50$ & $\$ 100$ & $\begin{array}{l}\$ 500 \text { to } \\
\$ 10,000\end{array}$ & TOTAL \\
\hline 2018 & 12.4 & 1.3 & 3.1 & 2.0 & 9.4 & 1.8 & 13.4 & 0.0004 & 43.4 \\
\hline 2017 & 12.1 & 1.2 & 3.0 & 2.0 & 9.2 & 1.7 & 12.5 & 0.0004 & 41.6 \\
\hline 2016 & 11.7 & 1.2 & 2.8 & 1.9 & 8.9 & 1.7 & 11.5 & 0.0004 & 39.8 \\
\hline 2015 & 11.4 & 1.1 & 2.7 & 1.9 & 8.6 & 1.6 & 10.8 & 0.0005 & 38.1 \\
\hline 2014 & 11.0 & 1.1 & 2.6 & 1.9 & 8.1 & 1.5 & 10.1 & 0.0005 & 36.4 \\
\hline 2013 & 10.6 & 1.0 & 2.5 & 1.8 & 7.7 & 1.5 & 9.2 & 0.0005 & 34.5 \\
\hline 2012 & 10.3 & 1.0 & 2.4 & 1.8 & 7.4 & 1.5 & 8.6 & 0.0005 & 33.0 \\
\hline 2011 & 10.0 & 0.9 & 2.4 & 1.7 & 7.1 & 1.4 & 7.8 & 0.0005 & 31.3 \\
\hline 2010 & 9.7 & 0.9 & 2.3 & 1.7 & 6.5 & 1.3 & 7.0 & 0.0005 & 29.5 \\
\hline 2009 & 9.6 & 0.9 & 2.2 & 1.6 & 6.4 & 1.3 & 6.6 & 0.0005 & 28.5 \\
\hline 2008 & 9.5 & 0.8 & 2.2 & 1.6 & 6.3 & 1.3 & 6.3 & 0.0005 & 27.9 \\
\hline 2007 & 9.3 & 0.8 & 2.2 & 1.6 & 6.1 & 1.3 & 5.7 & 0.0005 & 26.9 \\
\hline 2006 & 9.0 & 0.8 & 2.1 & 1.6 & 6.0 & 1.3 & 5.6 & 0.0005 & 26.4 \\
\hline 2005 & 8.8 & 0.7 & 2.1 & 1.6 & 5.8 & 1.2 & 5.4 & 0.0005 & 25.6 \\
\hline 2004 & 8.3 & 0.7 & 2.0 & 1.5 & 5.4 & 1.2 & 5.2 & 0.0005 & 24.2 \\
\hline 2003 & 8.2 & 0.7 & 1.9 & 1.5 & 5.4 & 1.2 & 4.9 & 0.0005 & 23.8 \\
\hline 2002 & 8.0 & 0.7 & 1.9 & 1.5 & 5.2 & 1.2 & 4.6 & 0.0005 & 22.9 \\
\hline 2001 & 7.8 & 0.6 & 1.8 & 1.5 & 5.0 & 1.1 & 4.2 & 0.0005 & 22.1 \\
\hline 2000 & 7.7 & 0.6 & 1.8 & 1.5 & 4.9 & 1.1 & 3.8 & 0.0005 & 21.3 \\
\hline 1999 & 7.5 & 0.6 & 1.8 & 1.6 & 5.8 & 1.3 & 3.9 & 0.0005 & 22.5 \\
\hline 1998 & 7.0 & 0.6 & 1.6 & 1.4 & 4.5 & 1.0 & 3.2 & 0.0005 & 19.3 \\
\hline
\end{tabular}

Includes Federal Reserve notes, U.S. notes, and currency no longer issued.

We still notice that the percentage of number of $\$ 100$ notes has been dramatically increasing since the

beginning of this century. However, we also realize that the speed of increase is not equal by each year. In 2000, we even see a slight decrease in the amount of $\$ 100$ notes in circulation. It is extremely hard for us to analyze what happened during that period of time (around year 2000); all the known sources point out that there was an economic recession during that period (2001-2002) due to the booming of the 90s generation. The whole recession was well-predicted by economists, hence much less financial and fiscal action was taken by the Government compared to an unpredicted recession. But there is a good evidence that can help explain the slight decrease in the amount of $\$ 100$ notes in circulation - the personal saving rate of Americans. 


\section{Personal saving rate in the United States from 1960 to 2019}

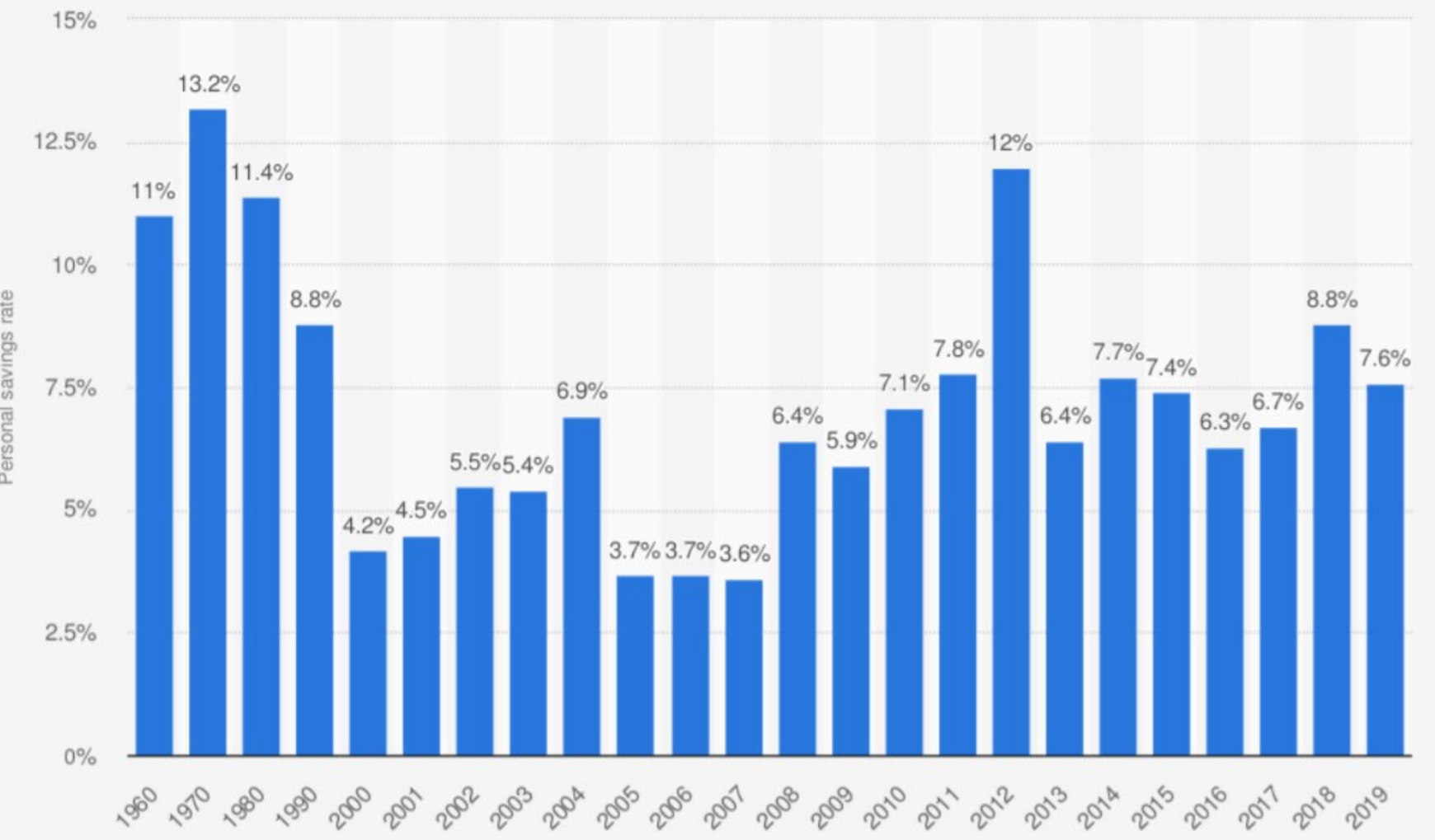

As can be seen in the graph, personal saving rate in the US suddenly dropped from about $8.8 \%$ in the 90 s to $4.2 \%$ in 2000 and kept at a low level between $3.5 \%$ and $6.9 \%$ until 2008. Respectively, during this period of time we see the increased speed of releasing $\$ 100$ notes into circulation. To calculate how fast the new $\$ 100$ note is released into circulation, we calculate the derivative of the change in total amount of $\$ 100$ notes in circulation over time $y(x)$ :

$$
S=\frac{\partial y}{\partial x}
$$

Here, $\partial x=1$ and $\partial y$ resembles the change between two different consecutive years. Below is the graph of how $S$ changes over time: 


\section{Rate of change in total number of $\$ 100$ notes in circulation}

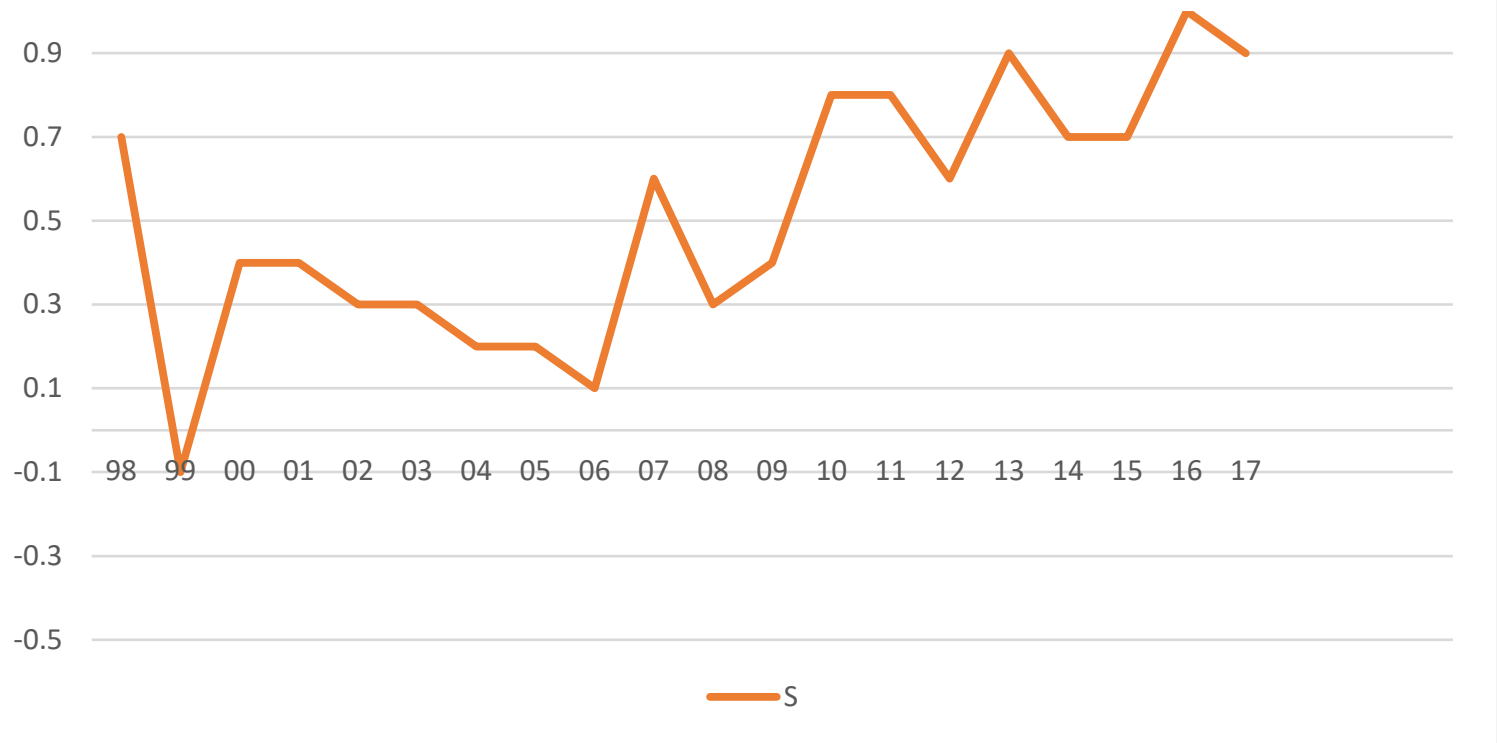

As can be seen, there is a sign of decrease of issuing $\$ 100$ notes between 2000 and 2008, while smaller notes are being issued more and more. This seems to go against the "most efficient solution" that we have talked about so far, as $S$ was decreasing while it was supposed to keep rising up like in the other periods. S was even negative in 1999, showing that the Federal Reserve System collected some cash back that year. It was due to the impact of the baby boomers, market activities and excessive spending which was reported to be in a large scale. Also, credit cards were not popular at that time, meaning people still had to use cash to pay for everything they bought, most of which cost even less than $\$ 100$. That pumped up the circulation of $\$ 20$ and smaller notes.

\section{CONCLUSION AND RECOMMENDATIONS}

The famous problem "Coin change" may still has application beyond its original purpose, in this case, in Finance and Fiscal policy. Each time the economy goes into a recession, different sets of phenomena show up resembling the type of recession and its effect to different areas of the economy. In some cases, money circulation is forced (or happens as a part of the recession) to be faster, which leads to a possible shortage of small-value notes and a possible excess of large-value notes. Thus, measures have to be taken to balance the leverage of demand-supply of money in the market, including those that go against the "knapsack theory" that have long been used in most cases. 
As of today, while the US has been combating with COVID-19, such economical and financial phenomena of a recession seem to appear one more time, as people spend most of their time at home and save most of their money for buying food and paying for essential bills. ATMs in most banks have only been capable of giving \$10 notes to withdrawers, which can become a nuisance for customers when they try to withdraw an accurate amount of money and have the remaining balance minus withdrawal fee just enough for a transaction. In this situation, the ability to solve such problems from banks is crucial, since every cancelled economic or financial activity at this moment hurts the already injured economy even more badly. A miscalculation that happens as underestimating the issue can lead to serial bankrupt or similar outcomes as of 2008. This research suggests that the Federal Reserve System should further increase the circulation of fast and short-life notes (\$20 and smaller notes). ATMs should now be able to give the exact amount of money needed for the customers, as the Federal Reserve Banks release smaller-note currency into circulation, starting from banks and ATMs themselves. It is, however, too soon to conclude exactly what the current market needs at present. Further calculation is crucial to determine the exact amount of the currency needed for circulation.

\section{NOMENCLATURE}

GCD: Greatest Common Divisor (of two or more integers) 


\section{REFERENCES}

1. Board of the Governors of the Federal Reserve System: Currency in Circulation: Volume. (2019) https://www.federalreserve.gov/paymentsystems/coin currcircvolume.htm

2. Wikipedia: Knapsack Problem (2020)

https://en.wikipedia.org/wiki/Knapsack_problem

3. M. Szmigiera: Personal saving rate in the U.S. 1960-2019 (Feb 17, 2020)

https://www.statista.com/statistics/246234/personal-savings-rate-in-the-united-states/

4. Federal Reserve Bank of New York: How currency get into circulation (July 2013)

https://www.newyorkfed.org/aboutthefed/fedpoint/fed01.html 